\title{
O panorama da vigilância de eventos adversos pós-vacinação ao fim da década de 2010: importância, ferramentas e desafios
}

\section{Surveillance of adverse events following immunization in the late 2010s: an overview of the importance, tools, and challenges}

El panorama de la vigilancia de eventos adversos posvacunación al final de la década de 2010: importancia, herramientas y desafíos
Patrícia Mouta Nunes de Oliveira 1

Letícia Kegele Lignani 1

Deborah Araújo da Conceição 1

Paula Molinari Cardoso de Mello Farias 1

Paulo Roberto Gomes Takey 1

Maria de Lourdes de Sousa Maia 1

Luiz Antonio Bastos Camacho 2

doi: 10.1590/0102-311X00182019

\section{Resumo}

A vacinação é uma das ações mais efetivas para proteger o indivíduo e a população contra doenças imunopreveníveis. Vacinas são produtos seguros e eficazes, porém, como qualquer outro medicamento, podem causar eventos adversos, que ganham maior visibilidade na medida em que as doenças são controladas, eliminadas ou erradicadas. Este trabalho analisou as ações de vigilância de eventos adversos pós-vacinação (EAPV) com base em dados da literatura científica e sites de programas de imunizações, agências reguladoras e de saúde, além da expertise dos autores nas áreas de imunizações e farmacovigilância. Com o aumento do número de vacinas no calendário básico e a ampliação do acesso da população, tornou-se fundamental o estabelecimento de um sistema eficiente de vigilância de EAPV no Brasil. Entretanto, a subnotificação de casos no Brasil e em outros países dificulta a detecção de EAPV, principalmente os raros. Informações sempre atualizadas sobre o benefício/ risco das vacinas permitem que programas de imunizações deem respostas rápidas e claras aos rumores de EAPV. Isso garante a confiabilidade no sistema, ainda mais diante do crescente movimento antivacinista e a influência cada vez maior das mídias sociais na opinião pública.

Imunização; Programas de Imunização; Vigilância de Produtos Comercializados

\author{
Correspondência \\ P. M. N. Oliveira \\ Instituto de Tecnologia em Imunobiológicos, Fundação \\ Oswaldo Cruz. \\ Av. Brasil 4365, Pavilhão Rocha Lima, Rio de Janeiro, \\ RJ 21040-900, Brasil. \\ patricia.mouta@bio.fiocruz.br \\ 1 Instituto de Tecnologia em Imunobiológicos, Fundação \\ Oswaldo Cruz, Rio de Janeiro, Brasil. \\ 2 Escola Nacional de Saúde Pública, Fundação Oswaldo Cruz, \\ Rio de Janeiro, Brasil.
}




\section{Introdução}

A imunização é uma das ações de saúde pública mais eficazes para proteger o indivíduo e a população contra doenças imunopreveníveis, sendo responsável por salvar milhões de vidas. As vacinas são produtos seguros e eficazes, porém, como qualquer outro medicamento, não são isentas de eventos adversos 1. Um evento adverso pós-vacinação (EAPV) é qualquer ocorrência médica indesejada após a vacinação, mas não tem necessariamente uma relação causal com o uso do produto, podendo ser um sintoma, doença ou um achado laboratorial anormal 2.

Dois fatores elevam a percepção de que as vacinas devem ser mais seguras que outros medicamentos ou tratamentos: (a) as vacinas são, normalmente, administradas em pessoas saudáveis e, por isto, há menor tolerância para os riscos quando comparadas a medicamentos administrados em pessoas doentes; (b) os EAPV ganham maior visibilidade da população, pois cada vez menos pessoas contraem a doença devido aos programas de imunizações consolidados, com recomendação universal, e às vezes obrigatória, com alta cobertura sustentada e vacinas eficazes, o que levou ao controle, eliminação e até erradicação de algumas doenças 3 .

Com a queda da prevalência de doenças imunopreveníveis como resultado de programas eficazes de imunizações, a vigilância e investigação dos EAPV tornaram-se ainda mais importantes para a saúde pública 4,5. Há maior preocupação sobre a qualidade e segurança das vacinas e mais informações são exigidas pelo público e profissionais de saúde. Nessa situação cada vez mais complexa, determinar se uma vacina é a causa de um EAPV ou se o mesmo é mera coincidência temporal requer uma investigação detalhada e uma avaliação cuidadosa da causalidade 1,5.

No Brasil, a vigilância dos EAPV é realizada pelo Programa Nacional de Imunizações (PNI) do Ministério da Saúde, pelos laboratórios produtores de vacinas, pelos profissionais de saúde e pela população usuária. A notificação e investigação adequada dos EAPV possibilitam a identificação correta dos eventos realmente causados pelas vacinas e o descarte de eventos coincidentes 6 . A vigilância de EAPV é parte da farmacovigilância, definida como a ciência e as atividades relativas à detecção, avaliação, compreensão e prevenção de eventos adversos ou de qualquer outro problema relacionado a medicamentos 7 .

Os registros de EAPV em indivíduos vacinados na rede pública são disponibilizados pelo Ministério da Saúde, por meio da Coordenação Geral do PNI (CGPNI), no Sistema de Informação da Vigilância de Eventos Adversos Pós-Vacinação (SI-EAPV) 8,9. O PNI iniciou a vigilância de EAPV em 1992, sendo a notificação compulsória instituída em 15 de julho de 2005 10. Para os serviços da rede privada a Agência Nacional de Vigilância Sanitária (Anvisa) disponibiliza o Sistema Nacional de Notificações para a Vigilância Sanitária (NOTIVISA) 11. Assim, os EAPV notificados no país procedem dessas duas fontes. Já as indústrias farmacêuticas devem reportar EAPV com seus produtos conforme a $R D C$ no 4/2009 da Anvisa 12,13.

A falta de resposta efetiva das autoridades de saúde a um evento atribuído a uma vacina pode afetar a confiança da população nos programas de vacinação e levar a quedas nas coberturas vacinais e retorno de doenças 5. Um estudo que avaliou a confiança nas vacinas e a hesitação em vacinar no Brasil entrevistou 952 pessoas, destas, 16,5\% demonstraram hesitação em vacinar. Dos cinco motivos mais citados pelos entrevistados para a hesitação em vacinar, três estão relacionados a dúvidas sobre segurança e efetividade das vacinas 14 . Para garantir a confiança do público nos programas nacionais de imunizações, os envolvidos no processo devem conhecer os EAPV e estar preparados para responder prontamente às questões de segurança, evitando a disseminação de notícias falsas e boatos 5 .

$\mathrm{Na}$ época atual, em que as fake news estão por toda parte e se espalham com velocidade alarmante, torna-se imperativo concentrar esforços na disseminação rápida e maciça de informações verdadeiras e confiáveis. A resposta oportuna às preocupações do público sobre a segurança das vacinas, e a comunicação efetiva, aumentam a confiança da população e preservam a integridade do programa de imunizações 8 .

De acordo com o estudo As Fake News Estão Nos Deixando Doentes? 15, 67\% dos entrevistados demonstraram acreditar em ao menos uma informação imprecisa sobre vacinas. A maioria das pessoas que não acredita na segurança das vacinas viu notícias negativas em redes sociais ou aplicativos de mensagens instantâneas. A disseminação de notícias falsas por intermédio de aplicativos de mensagens instantâneas levou o Ministério da Saúde a criar, em 2018, um canal para recebimento e apuração 
de notícias sobre saúde. Por meio do WhatsApp é possível encaminhar a mensagem recebida, que é analisada e respondida com a avaliação da veracidade 16.

O objetivo deste trabalho foi analisar as ações de vigilância de EAPV no Brasil, assim como em outros países, considerando dados publicados em literatura científica, sites dos programas de imunizações e agências reguladoras e de saúde, além da expertise dos autores nas áreas de imunizações e farmacovigilância.

\section{Panorama da vigilância de EAPV no mundo}

De acordo com dados publicados, $48 \%$ de todas as pessoas do mundo vivem em países sem sistemas de vigilância da segurança das vacinas 9 . O Plano de Ação Global para Vacinas (GVAP) da Organização Mundial da Saúde (OMS) identifica o estabelecimento e fortalecimento de sistemas de notificação de EAPV como uma atividade prioritária para os programas de imunizações, e define o índice de notificações de EAPV (número de EAPV por 100 mil nascidos vivos) como um indicador de desempenho para monitorar o progresso destes programas 9. Em 1999, a OMS criou o Comitê Consultivo Mundial sobre Segurança das Vacinas (GACVS) 4, com o objetivo de fortalecer as atividades de segurança no uso de vacinas. Esse comitê publica relatórios envolvendo questões de segurança, dando suporte aos programas de imunizações.

A avaliação contínua da segurança das vacinas requer a comparabilidade entre dados de ensaios clínicos e sistemas de vigilância. Para isso, são necessárias definições padronizadas de casos para eventos adversos e diretrizes para sua confirmação, registro e apresentação ${ }^{3}$. Em 2000, a OMS apoiou a criação da Colaboração Brighton 17, grupo que desenvolve definições padronizadas para eventos adversos. Esse grupo foi pioneiro na elaboração de diretrizes para a coleta, análise e apresentação padronizada de dados de segurança de vacinas 3 e, até o primeiro semestre de 2019, 61 diretrizes tinham sido desenvolvidas 17,18 .

Nos Estados Unidos, o Centro de Controle e Prevenção de Doenças (CDC), em conjunto com a Agência de Administração de Alimentos e Medicamentos (FDA), utilizam o sistema de notificação de eventos adversos VAERS (Vaccine Adverse Event Report System) para a vigilância de EAPV desde 1990 18. É um sistema de notificação passivo, obrigatório para profissionais de saúde e fabricantes, e acessível a qualquer cidadão. Por seu acesso amplo e base acessível, o VAERS é uma rica fonte de informação sobre segurança das vacinas, no entanto, os relatos devem ser considerados com cautela, pois nem sempre são verificados por profissionais de saúde. Os dados do VAERS são transmitidos para o Centro de Monitoramento Uppsala (UMC; Uppsala, Suécia), o centro colaborador da OMS para o monitoramento da segurança de medicamentos 19,20 .

Na Europa, o desenvolvimento da vigilância de EAPV foi heterogêneo 21. Atualmente, a Agência Europeia de Medicamentos (EMA) utiliza o EudraVigilance, um sistema que facilita o relato eletrônico de suspeitas de reações adversas relacionadas a medicamentos e a análise destes dados, permitindo a detecção oportuna de possíveis problemas de segurança 22. Essas informações estão disponíveis on-line para toda população e são um importante banco de dados para a consulta de suspeitas de reações adversas relacionada a medicamentos, incluindo as vacinas.

A vigilância de EAPV tem suas particularidades em cada país. Uma visão geral das semelhanças e diferenças entre alguns países é mostrada no Quadro 1 e permite a comparação entre programas de imunizações e seus respectivos sistemas de vigilância.

Países de diferentes continentes, com variados graus de desenvolvimento socioeconômico apresentam programas públicos de imunizações, exceto os Estados Unidos, onde o sistema de vacinação não é totalmente financiado pelo governo ${ }^{23}$. Em todos os países avaliados, a vigilância de EAPV é passiva, e três deles também realizam vigilância ativa. O gerenciamento dos dados de EAPV é realizado pelo programa de imunizações, pela agência reguladora ou por outras áreas do Ministério da Saúde. Nesses diferentes cenários, o acesso ao número de eventos adversos notificados varia substancialmente, dificultando o cálculo da taxa de relatos por 100 mil nascidos vivos.

A taxa de notificações de EAPV por 100 mil nascidos vivos foi proposta pelo GACVS e adotada pelo SAGE (Grupo Expertos em Assessoria Estratégica) da OMS como um indicador para identificar países com sistema de vigilância de EAPV bem estabelecido. Esse indicador vem sendo monitorado 
Quadro 1

Programas de imunizações e respectivos sistemas de vigilância de eventos adversos de alguns países.

\begin{tabular}{|c|c|c|c|c|c|c|c|c|}
\hline País & $\begin{array}{c}\text { Estimativa } \\
\text { da } \\
\text { população * }\end{array}$ & $\begin{array}{c}\text { Perfil do } \\
\text { programa } \\
\text { de imuniza- } \\
\text { ções }\end{array}$ & $\begin{array}{l}\text { Número de } \\
\text { vacinas no } \\
\text { portfólio do } \\
\text { programa }\end{array}$ & $\begin{array}{l}\text { Implemen- } \\
\text { tação do } \\
\text { sistema } \\
\text { vigilância } \\
\text { de EAPV }\end{array}$ & $\begin{array}{c}\text { Sistema de } \\
\text { vigilância } \\
\text { de EAPV em } \\
\text { uso }\end{array}$ & $\begin{array}{c}\text { Notificação } \\
\text { (quem } \\
\text { notifica?) }\end{array}$ & $\begin{array}{l}\text { Gerencia- } \\
\text { mento do } \\
\text { sistema de } \\
\text { vigilância } \\
\text { de EAPV }\end{array}$ & $\begin{array}{c}\text { Disponibilidade } \\
\text { dos dados de } \\
\text { EAPV }\end{array}$ \\
\hline Austrália 66,67 & 24,6 milhões & Público & 16 & 1997 & $\begin{array}{c}\text { Passiva e } \\
\text { ativa }\end{array}$ & $\begin{array}{l}\text { Profissionais } \\
\text { de saúde: } \\
\text { telefone; al- } \\
\text { guns estados } \\
\text { também dis- } \\
\text { ponibilizam } \\
\text { sites. } \\
\text { Consumi- } \\
\text { dores: for- } \\
\text { mulário } \\
\text { preenchido } \\
\text { enviado por } \\
\text { fax, e-mail ou } \\
\text { via postal; for- } \\
\text { mulário on- } \\
\text { line no site da } \\
\text { Administra- } \\
\text { ção de Bens } \\
\text { Terapêuticos } \\
\text { (TGA) }\end{array}$ & $\begin{array}{c}\text { TGA. } \\
\text { AusVaxSafety } \\
\text { - NCIRS } \\
\text { (Centro } \\
\text { Nacional de } \\
\text { Pesquisa e } \\
\text { Vigilância de } \\
\text { Imunização) }\end{array}$ & $\begin{array}{c}\text { Relatórios } \\
\text { periódicos de } \\
\text { vigilância de EAPV } \\
\text { disponibilizados } \\
\text { desde } 2003 \text { no site }\end{array}$ \\
\hline Brasil 19,68 & 209,3 milhões & Público & 18 & 1992 & Passiva & $\begin{array}{c}\text { Compulsória } \\
\text { para } \\
\text { profissionais } \\
\text { de saúde } \\
\text { (Sistema de } \\
\text { Informação } \\
\text { do Programa } \\
\text { Nacional de } \\
\text { Imunizações } \\
\text { - SI-PNI) e } \\
\text { indústria } \\
\text { (Sistema } \\
\text { Nacional de } \\
\text { Notificações } \\
\text { para a } \\
\text { Vigilância } \\
\text { Sanitária - } \\
\text { NOTIVISA). } \\
\text { Público } \\
\text { em geral } \\
\text { (NOTIVISA) }\end{array}$ & $\begin{array}{c}\text { Programa } \\
\text { Nacional de } \\
\text { Imunizações } \\
\text { (PNI): } \\
\text { Sistema de } \\
\text { Informação } \\
\text { da Vigilância } \\
\text { de Eventos } \\
\text { Adversos Pós- } \\
\text { Vacinação } \\
\text { (SI-EAPV). } \\
\text { Agência } \\
\text { Nacional de } \\
\text { Vigilância } \\
\text { Sanitária } \\
\text { (Anvisa): } \\
\text { NOTIVISA/ } \\
\text { VigiMed }\end{array}$ & $\begin{array}{l}\text { SI-PNI } \\
\text { disponibiliza } \\
\text { dados aos } \\
\text { produtores } \\
\text { após avaliação } \\
\text { e definição de } \\
\text { causalidade }\end{array}$ \\
\hline
\end{tabular}

(continua) 
Quadro 1 (continuação)

\begin{tabular}{|c|c|c|c|c|c|c|c|c|}
\hline País & $\begin{array}{c}\text { Estimativa } \\
\text { da } \\
\text { população * }\end{array}$ & $\begin{array}{c}\text { Perfil do } \\
\text { programa } \\
\text { de imuniza- } \\
\text { ções }\end{array}$ & $\begin{array}{l}\text { Número de } \\
\text { vacinas no } \\
\text { portfólio do } \\
\text { programa }\end{array}$ & $\begin{array}{l}\text { Implemen- } \\
\text { tação do } \\
\text { sistema } \\
\text { vigilância } \\
\text { de EAPV }\end{array}$ & $\begin{array}{c}\text { Sistema de } \\
\text { vigilância } \\
\text { de EAPV em } \\
\text { uso }\end{array}$ & $\begin{array}{l}\text { Notificação } \\
\text { (quem } \\
\text { notifica?) }\end{array}$ & $\begin{array}{l}\text { Gerencia- } \\
\text { mento do } \\
\text { sistema de } \\
\text { vigilância } \\
\text { de EAPV }\end{array}$ & $\begin{array}{c}\text { Disponibilidade } \\
\text { dos dados de } \\
\text { EAPV }\end{array}$ \\
\hline Canadá 69 & 37,1 milhões & Público & 19 & 1987 & $\begin{array}{c}\text { Passiva } \\
\text { (adulto); ativa } \\
\text { (crianças) }\end{array}$ & $\begin{array}{c}\text { Enfermeiros, } \\
\text { médicos e } \\
\text { farmacêu- } \\
\text { ticos que } \\
\text { trabalham na } \\
\text { imunização } \\
\text { ou no manejo } \\
\text { de EAPV. } \\
\text { Produtores } \\
\text { reportam } \\
\text { diretamente } \\
\text { ao Ministério } \\
\text { da Saúde. } \\
\text { Vigilância ati- } \\
\text { va pediátrica } \\
\text { para EAPV } \\
\text { selecionados } \\
\text { (Programa } \\
\text { Ativo de Mo- } \\
\text { nitoramento } \\
\text { da Imuniza- } \\
\text { ção - IMPACT) }\end{array}$ & $\begin{array}{l}\text { A Agência de } \\
\text { Saúde Pública } \\
\text { do Canadá } \\
\text { centraliza os } \\
\text { reportes de } \\
\text { EAPV de de- } \\
\text { partamentos } \\
\text { de saúde de } \\
\text { províncias e } \\
\text { territórios, } \\
\text { profissionais } \\
\text { de saúde e } \\
\text { da indústria } \\
\text { farmacêutica }\end{array}$ & $\begin{array}{c}\text { Relatórios } \\
\text { quadrimes trais } \\
\text { disponíveis (até } \\
\text { 2016) no site da } \\
\text { Agência de Saúde } \\
\text { Pública com } \\
\text { dados gerais }\end{array}$ \\
\hline China 70 & 1,4 bilhão & Público & 11 & 2005 & Passiva & $\begin{array}{c}\text { Serviços de } \\
\text { saúde, clíni- } \\
\text { cas de vacina- } \\
\text { ção, agências } \\
\text { de monito- } \\
\text { ramento de } \\
\text { reação ad- } \\
\text { versa a medi- } \\
\text { camentos, } \\
\text { fabricantes de } \\
\text { vacinas }\end{array}$ & $\begin{array}{l}\text { Ministério } \\
\text { da Saúde } \\
\text { e Agência } \\
\text { Regulatória } \\
\text { Chinesa }\end{array}$ & $\begin{array}{c}\text { Análise da } \\
\text { vigilância nacional } \\
\text { de EAPV publicada } \\
\text { mensalmente } \\
\text { no boletim do } \\
\text { programa de } \\
\text { imunização, } \\
\text { distribuído ao } \\
\text { Centro Chinês } \\
\text { de Controle e } \\
\text { Prevenção de } \\
\text { Doenças (CDC) } \\
\text { e compartilhado } \\
\text { com as agências } \\
\text { de monitoramen } \\
\text { to eventos } \\
\text { adversos }\end{array}$ \\
\hline
\end{tabular}


Quadro 1 (continuação)

\begin{tabular}{|c|c|c|c|c|c|c|c|c|}
\hline País & $\begin{array}{c}\text { Estimativa } \\
\text { da } \\
\text { população * }\end{array}$ & $\begin{array}{c}\text { Perfil do } \\
\text { programa } \\
\text { de imuniza- } \\
\text { ções }\end{array}$ & $\begin{array}{l}\text { Número de } \\
\text { vacinas no } \\
\text { portfólio do } \\
\text { programa }\end{array}$ & $\begin{array}{l}\text { Implemen- } \\
\text { tação do } \\
\text { sistema } \\
\text { vigilância } \\
\text { de EAPV }\end{array}$ & $\begin{array}{l}\text { Sistema de } \\
\text { vigilância } \\
\text { de EAPV em } \\
\text { uso }\end{array}$ & $\begin{array}{c}\text { Notificação } \\
\text { (quem } \\
\text { notifica?) }\end{array}$ & $\begin{array}{l}\text { Gerencia- } \\
\text { mento do } \\
\text { sistema de } \\
\text { vigilância } \\
\text { de EAPV }\end{array}$ & $\begin{array}{c}\text { Disponibilidade } \\
\text { dos dados de } \\
\text { EAPV }\end{array}$ \\
\hline Cuba 71,72 & 11,4 milhões & Público & 13 & 1996 & $\begin{array}{c}\text { Ativa } \\
\text { (menores } \\
\text { de } 1 \text { ano); } \\
\text { passiva } \\
\text { (demais } \\
\text { grupos } \\
\text { etários) }\end{array}$ & $\begin{array}{c}\text { Em } \\
\text { formulário } \\
\text { próprio, } \\
\text { profissionais } \\
\text { de saúde e } \\
\text { indústrias }\end{array}$ & $\begin{array}{c}\text { Centro para } \\
\text { o Controle } \\
\text { Estatal de } \\
\text { Medicamen- } \\
\text { tos, Equipes } \\
\text { e Dispositivos } \\
\text { Médicos } \\
\text { (CECMED)/ } \\
\text { Ministério da } \\
\text { Saúde }\end{array}$ & $\begin{array}{l}\text { Boletins } \\
\text { periódicos com } \\
\text { informações } \\
\text { gerais }\end{array}$ \\
\hline $\begin{array}{l}\text { Estados } \\
\text { Unidos } 73\end{array}$ & 327,2 milhões & Privado & 12 & 1990 & Passiva & $\begin{array}{l}\text { Profissionais } \\
\text { de saúde, } \\
\text { produtores } \\
\text { e público em } \\
\text { geral }\end{array}$ & $\begin{array}{c}\text { O Sistema de } \\
\text { Notificação } \\
\text { de Eventos } \\
\text { Adversos } \\
\text { de Vacinas } \\
\text { (VAERS) é co- } \\
\text { administrado } \\
\text { pelo Centro } \\
\text { de Controle } \\
\text { e Prevenção } \\
\text { de Doenças } \\
\text { (CDC) e pela } \\
\text { Agência de } \\
\text { Adminis- } \\
\text { tração de } \\
\text { Alimentos e } \\
\text { Medicamen- } \\
\text { tos (FDA) }\end{array}$ & $\begin{array}{c}\text { Público, por meio } \\
\text { do sistema VAERS } \\
\text { Wonder }\end{array}$ \\
\hline Gana 74 & 29,4 milhões & Público & 9 & $\begin{array}{c}\text { Não } \\
\text { informado }\end{array}$ & Passiva & $\begin{array}{l}\text { Profissionais } \\
\text { de saúde, } \\
\text { consumi- } \\
\text { dores, produ- } \\
\text { tores }\end{array}$ & $\begin{array}{c}\text { Programa } \\
\text { expandido de } \\
\text { imunizações } \\
\text { coordena o } \\
\text { monitora- } \\
\text { mento de } \\
\text { EAPV } \\
\end{array}$ & $\begin{array}{c}\text { Dados de } \\
\text { farmacovigilância } \\
\text { local não } \\
\text { disponíveis no site }\end{array}$ \\
\hline Índia 75 & 1,35 bilhão & Público & 11 & 1988 & Passiva & $\begin{array}{c}\text { Em } \\
\text { formulário } \\
\text { eletrônico } \\
\text { (eCRF), } \\
\text { profissionais } \\
\text { de saúde e } \\
\text { indústrias }\end{array}$ & $\begin{array}{l}\text { Agência } \\
\text { reguladora }\end{array}$ & $\begin{array}{c}\text { Boletins na } \\
\text { Internet com } \\
\text { análise de dados } \\
\text { de EAPV }\end{array}$ \\
\hline
\end{tabular}

(continua) 
Quadro 1 (continuação)

\begin{tabular}{|c|c|c|c|c|c|c|c|c|}
\hline País & $\begin{array}{c}\text { Estimativa } \\
\text { da } \\
\text { população * }\end{array}$ & $\begin{array}{c}\text { Perfil do } \\
\text { programa } \\
\text { de imuniza- } \\
\text { ções }\end{array}$ & $\begin{array}{l}\text { Número de } \\
\text { vacinas no } \\
\text { portfólio do } \\
\text { programa }\end{array}$ & $\begin{array}{l}\text { Implemen- } \\
\text { tação do } \\
\text { sistema } \\
\text { vigilância } \\
\text { de EAPV }\end{array}$ & $\begin{array}{l}\text { Sistema de } \\
\text { vigilância } \\
\text { de EAPV em } \\
\text { uso }\end{array}$ & $\begin{array}{c}\text { Notificação } \\
\text { (quem } \\
\text { notifica?) }\end{array}$ & $\begin{array}{l}\text { Gerencia- } \\
\text { mento do } \\
\text { sistema de } \\
\text { vigilância } \\
\text { de EAPV }\end{array}$ & $\begin{array}{c}\text { Disponibilidade } \\
\text { dos dados de } \\
\text { EAPV }\end{array}$ \\
\hline Paquistão 76,77 & 200,8 milhões & Público & 9 & 2016 & Passiva & $\begin{array}{c}\text { Não } \\
\text { informado }\end{array}$ & $\begin{array}{c}\text { Não } \\
\text { informado }\end{array}$ & $\begin{array}{c}\text { Dados de } \\
\text { farmacovigilância } \\
\text { local não } \\
\text { disponíveis no site }\end{array}$ \\
\hline $\begin{array}{l}\text { Reino } \\
\text { Unido } 78,79\end{array}$ & 66,5 milhões & Público & 14 & 1964 & Passiva & $\begin{array}{c}\text { Passiva; } \\
\text { público, } \\
\text { produtores e } \\
\text { profissionais } \\
\text { de saúde. } \\
\text { Cada país tem } \\
\text { seu sistema } \\
\text { de notificação } \\
\text { (na Inglaterra } \\
\text { é o Yellow } \\
\text { Card) }\end{array}$ & $\begin{array}{l}\text { Agência Regu- } \\
\text { ladora de } \\
\text { Medicamen- } \\
\text { tos e Produ- } \\
\text { tos para a } \\
\text { Saúde }\end{array}$ & $\begin{array}{c}\text { EudraVigilance } \\
\text { disponibiliza } \\
\text { dados de toda a } \\
\text { Europa }\end{array}$ \\
\hline
\end{tabular}

EAPV: eventos adversos pós-vacinação.

* Segundo dados da Organização Mundial da Saúde 80.

em níveis mundial e nacional. Em 2017, 114 países reportaram mais de 10 eventos/100 mil nascidos vivos, um aumento significativo (> 40\%) se comparado aos dados de 2010 24,25.

Em 2016, houve um movimento para a melhoria dos sistemas de vigilância em países em desenvolvimento, com base na iniciativa Global Vaccine Safety Blueprint. O objetivo era auxiliar países em desenvolvimento a montar planos de trabalho e desenvolver sistemas de vigilância. Foram criados comitês nacionais para assessorar a elaboração de normas e protocolos para a vigilância de EAPV.

Até 2016, o Brasil relatava mais de 10 EAPV/100 mil nascidos vivos, mas no relatório de 2017 a frequência de notificações foi menor, mostrando um cenário preocupante de piora do sistema nacional de vigilância de EAPV 24,25.

Outra diferença observada entre os países avaliados é o número de doenças imunopreveníveis abrangidas pelo calendário básico de imunizações, conforme mostra o Quadro 2. Além da variação no número de vacinas, a oferta de vacinas mais reatogênicas, como a BCG e a vacina combinada de difteria, tétano e pertussis de células inteiras pode afetar a frequência de notificações de EAPV.

\section{Panorama da vigilância de EAPV no Brasil}

No Brasil, o PNI foi instituído pelo Ministério da Saúde em 1973, iniciando uma nova etapa na história das políticas de saúde pública, com foco na prevenção e contribuindo para a redução da morbidade e mortalidade por doenças transmissíveis 26 . As ações de vacinação já eram realizadas no país, mas sem uma coordenação que as organizasse 27.

Com o aumento do número de vacinas no calendário básico ao longo dos anos e a ampliação do acesso da população, tornou-se fundamental o estabelecimento de um sistema de vigilância de EAPV. Seguindo tendência internacional, em 1991 foi criado o Comitê Técnico Assessor em Imunizações (CTAI) como um fórum permanente de assessoria técnico-científica ao PNI. Ainda naquele ano, foi iniciada a elaboração de fichas de notificação, definição de fluxos de trabalho e normatização de 


\section{Quadro 2}

Disponibilidade das vacinas nos programas nacionais de imunizações de alguns países.

\begin{tabular}{|c|c|c|c|c|c|c|c|c|c|c|c|}
\hline Vacina & Brasil 81 & $\begin{array}{c}\text { Estados } \\
\text { Unidos } \\
82\end{array}$ & $\begin{array}{l}\text { Cana- } \\
\text { dá } 59\end{array}$ & $\begin{array}{l}\text { Austrá- } \\
\text { lia } 60\end{array}$ & $\begin{array}{c}\text { Reino } \\
\text { Unido } 83\end{array}$ & $\begin{array}{l}\text { Méxi- } \\
\text { co } 84\end{array}$ & China 70 & Gana 85 & Cuba 61 & $\begin{array}{l}\text { Paquis- } \\
\text { tão } 77\end{array}$ & Índia 86 \\
\hline BCG & & & * & & ** & & & & & & \\
\hline Hepatite A & & & * & & ** & & & & & & \\
\hline \multicolumn{12}{|l|}{ Hepatite B } \\
\hline \multicolumn{12}{|l|}{$\begin{array}{l}\text { Tríplice bacteriana } \\
\text { (DTPw ou DTPa ou } \\
\text { combinadas com } \\
\text { Hepatite B, IPV e/ou } \\
\text { Hib) }\end{array}$} \\
\hline \multicolumn{12}{|l|}{$\begin{array}{l}\text { Haemophilus } \\
\text { influenzae B }\end{array}$} \\
\hline \multicolumn{12}{|l|}{ Poliomielite inativada } \\
\hline Poliomielite oral & 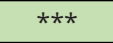 & & & & & $\star \star \star *$ & $* \star *$ & & & & \\
\hline \multicolumn{12}{|l|}{ Rotavírus } \\
\hline \multicolumn{12}{|l|}{$\begin{array}{l}\text { Pneumocócica } \\
\text { conjugada (7, } 10 \text { ou } \\
\text { 13-valente) }\end{array}$} \\
\hline \multicolumn{12}{|l|}{$\begin{array}{l}\text { Meningocócicas } \\
\text { conjugadas } \\
\text { (C ou ACWY) }\end{array}$} \\
\hline \multicolumn{12}{|l|}{ Meningocócica B } \\
\hline Influenza & ** & & & & & & & & & & \\
\hline \multicolumn{12}{|l|}{ Febre amarela } \\
\hline \multicolumn{12}{|c|}{$\begin{array}{l}\text { Tríplice viral (sarampo, } \\
\text { caxumba, rubéola) }\end{array}$} \\
\hline $\begin{array}{l}\text { Dupla viral } \\
\text { (sarampo, rubéola) }\end{array}$ & $\#$ & $\#$ & $\#$ & $\#$ & $\#$ & \# & & & $\#$ & & \\
\hline Sarampo & $\#$ & $\#$ & $\#$ & $\#$ & $\#$ & $\#$ & $\#$ & & $\#$ & & $\#$ \\
\hline \multicolumn{12}{|l|}{$\begin{array}{l}\text { Varicela (isolada ou } \\
\text { vacina tetraviral) }\end{array}$} \\
\hline \multicolumn{12}{|l|}{ HPV } \\
\hline $\begin{array}{l}\text { Pneumocócica } \\
\text { polissacarídica }\end{array}$ & ** & & * & & & & & & & & \\
\hline dTpa & $\star \star$ & & & & & & & & & & \\
\hline Herpes zoster & & & * & ** & ** & & & & & & \\
\hline
\end{tabular}

Nota: verde = disponível; branco = indisponível ou não utilizada pelo país.

* Recomendada em algumas províncias do país;

** Disponível para alguns grupos populacionais específicos, de acordo com a estratégia de imunização;

*** Imunização sequencial (reforços e campanhas);

\# Doenças imunizadas com o uso de vacina tríplice viral ou só de sarampo. 
condutas clínicas. A capacitação das equipes municipais e estaduais envolvidas nas ações de imunização tem sido essencial para aumentar a sensibilidade do sistema na captação de casos de EAPV 6. A necessidade de orientar e padronizar a notificação e investigação dos casos de EAPV levou o Ministério da Saúde a publicar, em 1998, a primeira edição do Manual de Vigilância Epidemiológica de Eventos Adversos Pós-Vacinação, que está na 3ạ edição, publicada em 2014 6. Em 2000, as notificações passaram a ser informatizadas pelo SI-EAPV.

Os EAPV foram incluídos na lista de agravos de notificação compulsória em 2005 28, e permanecem até hoje. O objetivo foi aumentar a captação dos casos de EAPV nos serviços públicos e privados, e permitir a adoção de medidas de controle pertinentes pelos órgãos públicos. Essa inclusão tornou obrigatória para profissionais de saúde a notificação de EAPV graves e óbitos após a vacinação 29 .

Em 2008, foi criado o Comitê Interinstitucional de Farmacovigilância de Vacinas e Outros Imunobiológicos (CIFAVI), constituído pela Anvisa, pelo CGPNI/Secretaria de Vigilância em Saúde do Ministério da Saúde (SVS/MS) e Instituto Nacional de Controle de Qualidade em Saúde da Fundação Oswaldo Cruz (INCQS/Fiocruz), para promover ações articuladas entre os componentes do sistema de vigilância 30 .

Apesar da vigilância de EAPV vinculada ao PNI ter começado no início da década de 1990, a regulamentação dos sistemas de farmacovigilância para os produtores de vacinas ocorreu apenas em 2009, a partir da $R D C$ no 04/2009 13. Essa norma representou um grande avanço na vigilância póscomercialização de medicamentos no Brasil, estabelecendo ações de farmacovigilância às indústrias, que vão desde a notificação compulsória dos EAPV relacionados ao uso de seus produtos até o desenvolvimento de uma estrutura capaz de monitorar a segurança dos medicamentos comercializados 31 .

Há uma tendência mundial em harmonizar as normas de farmacovigilância entre os países, de forma a permitir a avaliação conjunta dos dados. Nesse sentido, a Anvisa tornou-se em 2016 membro do Conselho Internacional para Harmonização de Requisitos Técnicos para Medicamentos de Uso Humano (ICH), conselho que reúne autoridades reguladoras e associações de indústrias farmacêuticas para discutir aspectos técnicos e científicos relacionados ao registro de medicamentos 32 . No prazo de cinco anos a partir do ingresso nesse conselho, a agência deverá se adequar a um conjunto de cinco guias do ICH que padronizam práticas de Farmacovigilância e Pesquisa Clínica.

Além de implantar um conjunto de especificações para padronizar o processo de registro de medicamentos conhecido como Common Technical Document (CTD), a Anvisa também passará a utilizar o dicionário médico para atividades regulatórias (MedDRA - Medical Dictionary for Regulatory Activites) 33. Portanto, as normas e resoluções relativas à Farmacovigilância para DRM (Detentores de Registro de Medicamentos) deverão ser atualizadas para atender a esse novo cenário.

A principal diferença entre as ações de farmacovigilância executadas pelo PNI e pela Anvisa é a fonte da notificação. O PNI recebe as notificações dos profissionais de saúde das salas de vacina do sistema público de saúde, a Anvisa recebe notificações dos fabricantes, serviços privados de vacinação e de qualquer cidadão, seja ele profissional de saúde ou não. Os sistemas para notificação e formulários, entretanto, são diferentes para a população em geral, profissionais de saúde e fabricantes, permitindo uma ampla captação de eventos adversos. Os serviços de saúde da esfera privada fazem a notificação de EAPV à Anvisa 6,10. Atualmente, o NOTIVISA está sendo substituído gradativamente pelo VigiMed. A evolução de dois sistemas paralelos e complementares para a captação e registro de EAPV, gerenciados pela Anvisa e pelo PNI, poderia melhorar a sensibilidade, em geral baixa, dos sistemas passivos. Pode-se observar uma evolução desse sistema no Brasil nas últimas décadas (Figura 1).

\section{Por que investigar um EAPV?}

As vacinas passam por um rigoroso processo até o seu registro pelas agências reguladoras, incluindo estudos pré-clínicos e vários estudos clínicos. Porém, a população estudada em um ensaio clínico é selecionada e todos os fatores são controlados. Além disso, por maior que seja um estudo clínico, ele não permite a inclusão de milhares de pessoas e nem a avaliação de populações especiais (como idosos, 


\section{Figura 1}

Linha do tempo da evolução do Programa Nacional de Imunizações (PNI) e sistemas de vigilância de eventos adversos pós-vacinação (EAPV).

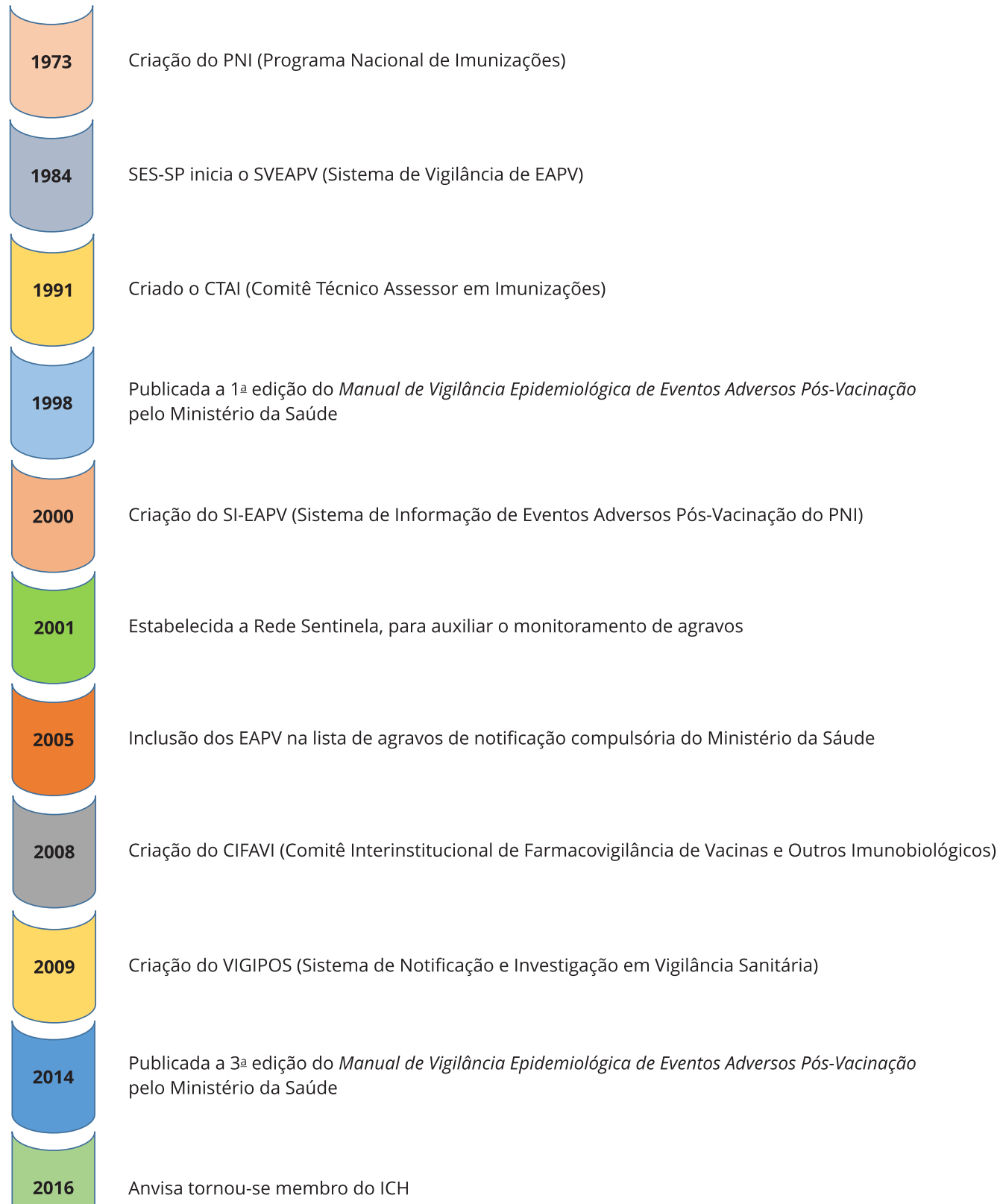

Anvisa: Agência Nacional de Vigilância Sanitária; ICH: Conselho Internacional para Harmonização de Requisitos Técnicos para Medicamentos de Uso Humano; SES-SP: Secretaria Estadual de Saúde de São Paulo. 
gestantes, entre outros). Por isso, a manutenção da vigilância das vacinas após sua introdução no mercado, realizada por atividades de farmacovigilância, é fundamental para garantir a manutenção da sua eficácia e segurança 18 .

A notificação e investigação de EAPV contribuem para a identificação de complicações raras ou inesperadas das imunizações, caracterização de possíveis sinais de segurança das vacinas e também podem identificar um aumento na frequência de eventos esperados. As notificações de EAPV são captadas por sistemas de informação em saúde como o SI-PNI e o NOTIVISA.

De acordo com a OMS, esses sistemas devem gerar, compilar, analisar e sintetizar dados relacionados à saúde, permitindo seu uso e comunicação. Os dados notificados, em conjunto com outras informações, como determinantes de saúde e desempenho dos sistemas de saúde, por exemplo, servem como base para a tomada de decisões. Além de essenciais ao monitoramento e avaliação, os sistemas de saúde são importantes também para outras finalidades, como apoio ao gerenciamento de pacientes e unidades de saúde, acompanhamento de tendências e apoio para relatórios globais, entre outras 34. Alguns episódios bem documentados ilustram o papel da vigilância dos EAPV na garantia da segurança das vacinas, como descrito a seguir.

Os surtos de meningite asséptica associados à vacina tríplice viral (TVV) aplicada em campanhas de vacinação nos estados da Bahia, Ceará, Mato Grosso, Mato Grosso do Sul, Piauí e Rio Grande do Sul, entre 1997 e 1998, trouxeram importante contribuição ao aperfeiçoamento da vigilância epidemiológica de EAPV 35,36. A investigação detalhada desses episódios sugeriu associação com o uso da TVV e embasou o PNI na troca do fabricante da vacina usada no país, garantindo a segurança e mantendo a confiança dos profissionais de saúde e da população no sistema.

A vacina para rotavírus nos mostra outra situação em que o monitoramento de EAPV foi essencial. Após o registro da primeira vacina rotavírus (Rotashield; Wyeth Laboratories) nos Estados Unidos, em agosto de 1998, foi demonstrada sua associação com um aumento de mais de 30 vezes no risco de intussuscepção (um evento adverso grave), na semana seguinte ao recebimento da primeira dose 37 , o que levou à sua retirada do mercado pelo fabricante em 1999 38,39.

No Brasil, outra vacina rotavírus, a RV1 (parceria entre o Instituto de Tecnologia em Imunobiológicos da Fiocruz - Bio-Manguinhos - e a GlaxoSmithKline - GSK) foi introduzida no calendário de imunizações do PNI em março de 2006 para crianças menores de um ano de idade 38 . E em maio de 2007, o México também incluiu a RV1 em seu programa de imunizações. Em ambos os países a vacina é recomendada aos dois e quatro meses de idade, devendo ser iniciada, no mais tardar, às 15 semanas de vida. Brasil e México juntos somavam, à época da introdução da RV1, cerca de 6 milhões de nascimentos ao ano, ocasião favorável para avaliar se havia associação da vacinação com o aumento do risco de intussuscepção. Diante disso, foi conduzido um estudo caso/controle em 53 hospitais de sete estados brasileiros e 16 hospitais em dez estados mexicanos no período de agosto de 2008 a agosto de 201040.

Como resultado do estudo foi observado um aumento no risco de intussuscepção na primeira semana após a vacinação no México, já no Brasil um possível risco foi observado apenas na primeira semana após a segunda dose. Esses riscos aumentados foram traduzidos em um excesso de 96 casos de intussuscepção e cinco mortes nos dois países combinados, números que são superados pelos benefícios da vacinação, que anualmente previne mais de 80 mil hospitalizações e 1.300 mortes nos dois países 40 .

A primeira vacina para dengue registrada no Brasil (Dengvaxia; Sanofi-Pasteur) é mais um exemplo de produto que teve a indicação alterada devido aos resultados obtidos durante a vigilância pós-mercado ${ }^{41}$. Existem quatro sorotipos de vírus de dengue, e a exposição a um deles não confere imunidade aos outros. Além disso, é sabido que em uma segunda infecção, por um sorotipo diferente, há maior risco do desenvolvimento de uma forma grave da doença devido a um fenômeno conhecido como "exacerbação dependente de anticorpos" (antibody-dependent enhancement - ADE) 42. A vacina confere proteção para os quatro sorotipos, mas a eficácia estimada para indivíduos acima de nove anos foi de aproximadamente 58\%, 47\%, 74\% e 83\% para os sorotipos 1, 2, 3 e 4, respectivamente 43.

Em novembro de 2017, cerca de dois anos após o registro da vacina, a fabricante alertou sobre o aumento do risco de dengue grave em pessoas previamente soronegativas 42 . Dados de acompanhamento dos estudos clínicos demonstraram que indivíduos soronegativos antes da vacinação, quando vacinados desenvolveram anticorpos não protetores contra dengue, o que poderia funcionar como 
uma primo-infecção e levar ao fenômeno de ADE em caso de exposição ao vírus da dengue, portanto, a um quadro clínico mais grave 44,45. Assim, houve alteração na indicação da vacina pela Anvisa, que passou a recomendar seu uso apenas para pessoas que já tenham tido ao menos uma infecção por um dos sorotipos do vírus 46,47.

Outro exemplo da importância da vigilância de EAPV é o caso da vacina tetravalente bacteriana celular (DTP-Hib), que em 2002 começou a ser usada no Brasil. O PNI recebeu de alguns estados brasileiros, pelo sistema de vigilância passiva de EAPV, relatos sobre o aumento da frequência de eventos adversos relacionados temporalmente com essa vacina, principalmente episódios hipotônico-hiporresponsivos (EHH). Esses dados, no entanto, foram considerados inconclusivos e contraditórios. Por esse motivo, foi realizado um estudo de vigilância ativa, patrocinado pelo Ministério da Saúde, com o objetivo de avaliar a incidência de EHH e outros eventos adversos graves após a administração da vacina 48 .

Uma coorte de 21.064 lactentes foi acompanhada na cidade do Rio de Janeiro por 48 horas após a aplicação da DTP-Hib. A incidência de EHH encontrada foi de 1:1.744 doses (casos confirmados) e de 1:1.495 doses (casos suspeitos que incluem os confirmados), e a taxa de incidência de convulsões foi de 1:5.231 doses. Não foram detectados casos de apneia. Os resultados foram comparáveis àqueles relatados na literatura para essa vacina. Esse estudo possibilitou ao PNI responder de forma ágil e robusta à questão levantada pelo sistema de vigilância passiva e garantir o uso seguro e confiável da vacina 48 .

Esse estudo foi utilizado como base para um outro, conduzido no Município de Araraquara (São Paulo), com o objetivo de avaliar a sensibilidade de um sistema de vigilância passiva no período de 2000 a 2013. O trabalho usou a frequência de EHH e convulsões como eventos sentinela, considerando a taxa relatada no estudo de vigilância ativa como padrão ouro. Os autores calcularam a sensibilidade do sistema de vigilância passiva como de $71.9 \%$ e 78,9\% para EHH e convulsões, respectivamente, e concluíram que, se bem conduzido, um sistema de vigilância passiva pode ser um bom termômetro para alterações de perfil de segurança das vacinas 49 .

\section{Como investigar um EAPV?}

Os elementos essenciais do conceito de EAPV são a temporalidade e a plausibilidade biológica, o que torna a definição de caso para fins de vigilância operacionalmente simples e objetiva. Se por um lado essa concepção maximiza a sensibilidade da captação dos eventos com potencial associação à vacina, por outro, torna necessária a investigação destes casos para estabelecer se o envolvimento da vacina é mais provável do que outras alternativas 39 . Por exemplo, a vacina para rotavírus RotaShield foi retirada do mercado americano voluntariamente pelo fabricante menos de um ano após a sua introdução, quando os dados de monitoramento de notificações de EAPV mostraram um risco adicional de 1 a 2 casos de intussuscepção por 10 mil lactentes vacinados 39 .

A investigação de um EAPV tem por objetivo principal determinar se a vacina/vacinação foi ou não a responsável pela ocorrência do evento. A coleta de informações é crucial para o processo de investigação e envolve dados clínicos, epidemiológicos e laboratoriais, além de informações sobre o produto administrado. Para isso, é necessário o envolvimento das equipes das salas de vacinação, vigilância epidemiológica, equipes assistenciais, laboratórios de referência e nível central (PNI).

Além da coleta de informações, muitas vezes é necessária a coleta de amostras clínicas que, se não executada no tempo correto, pode comprometer ou mesmo inviabilizar a conclusão da investigação. Eventos adversos graves ou clusters de EAPV devem ser investigados imediatamente nesses casos, e o tempo é fundamental para o sucesso da investigação. Uma amostra não coletada no momento ideal, não armazenada adequadamente ou não transportada corretamente pode comprometer todo o processo.

As informações necessárias para investigar de modo satisfatório um EAPV, permitindo estabelecimento da causalidade, são descritas no Quadro 3.

Quando um caso suspeito é detectado, o serviço de saúde deve notificar prontamente a vigilância epidemiológica, que deve iniciar a investigação em até 48 horas. A partir daí, com o caso já inserido 
Quadro 3

Informações que devem ser coletadas durante a investigação de um evento adverso pós-vacinação (EAPV).

\begin{tabular}{|c|c|c|}
\hline \multicolumn{2}{|c|}{ VARIÁVEIS } & DESCRIÇÃO \\
\hline 1 & Dados demográficos & Idade, sexo, local de residência, contatos \\
\hline 2 & História da doença atual & Sintomas/Sinais, cronologia, data de início e duração, tratamento, diagnóstico e desfecho \\
\hline 3 & História familiar & Doenças em pessoas da família (genéticas, autoimunes etc.) \\
\hline 4 & História patológica pregressa & $\begin{array}{l}\text { Eventos adversos com doses anteriores da vacina, alergias, doenças de base, uso de } \\
\text { medicamentos }\end{array}$ \\
\hline 5 & História vacinal & $\begin{array}{c}\text { Vacinas recebidas com número de lote, número de doses recebidas, data da vacina, local de } \\
\text { administração (especialmente vacinas recebidas nos } 30 \text { dias anteriores ao evento e doses } \\
\text { anteriores da vacina suspeita do EAPV) }\end{array}$ \\
\hline 6 & Resultados laboratoriais & Resultados de exames (laboratoriais, imagens etc.) realizados para a investigação do evento \\
\hline 7 & Desfecho & Informações da declaração de óbito e relatório de autopsia (se aplicável) \\
\hline 8 & Vacina(s) suspeita(s) do EAPV & $\begin{array}{l}\text { Número do lote, fabricante, informações sobre o armazenamento da vacina, se alterações foram } \\
\text { detectadas pela equipe local, local da vacinação (nome da unidade de saúde), informações sobre } \\
\text { casos semelhantes com o mesmo lote ou no mesmo local de vacinação }\end{array}$ \\
\hline 9 & Qualidade da(s) vacina(s) suspeita(s) & Informações referentes ao controle de qualidade da(s) vacina(s) suspeita(s) \\
\hline
\end{tabular}

Fonte: adaptado da Organização Mundial da Saúde 87.

no SI-EAPV, ele é encaminhado às coordenações regionais, e então às estaduais. Os dados iniciais inseridos no sistema vão sendo atualizados na medida em que novas informações são obtidas 6 .

De acordo com a Portaria no 204/2016, todo profissional de saúde em exercício de suas atividades tem a obrigação de notificar um caso de EAPV ao gestor do Sistema Único de Saúde (SUS), mesmo que se trate de estabelecimento da rede privada 29.

A investigação de um EAPV inclui a coleta de dados, classificação do caso conforme a gravidade (grave, não grave), intensidade (leve, moderado, intenso), previsibilidade (descrito ou não em bula) e a avaliação de causalidade (consistente, indeterminado, coincidente ou inclassificável). É necessário também que os eventos adversos sejam codificados em termos médicos para facilitar a comparação entre casos. Atualmente, a terminologia mais usada é a do MedDRA, criado no fim da década de 1990 pelo ICH 33 . Essa terminologia é padronizada, completa e altamente específica, facilitando a troca de informações regulatórias internacionalmente 32.

A etapa mais importante e mais difícil na investigação de um EAPV é a avaliação de causalidade, cujo objetivo é determinar se há relação de causa e efeito entre vacina/vacinação e EAPV. Essa análise se baseia principalmente na relação temporal entre a administração da vacina e o evento, na plausibilidade médica ou farmacológica (sinais e sintomas, exames laboratoriais, achados patológicos, mecanismo de ação) e na probabilidade ou exclusão de outras causas. Nessa etapa todas as informações disponíveis sobre o caso já devem estar acessíveis 50 .

Em 2012, a classificação de causalidade específica para EAPV foi revisada pelo Conselho para Organizações Internacionais de Ciências Médicas (CIOMS) e pela OMS, e está em uso atualmente também no Brasil pelo PNI 6,51. O uso de definições de caso padronizadas é uma ferramenta facilitadora para as investigações de EAPV. A Colaboração Brighton publicou em 2004 suas primeiras definições de caso, recomendadas pela Academia Americana de Pediatria, CIOMS, EMA, FDA, entre outras organizações 52 .

Um dos eventos adversos que tem definição de caso pela Colaboração Brighton é a doença viscerotrópica aguda associada à vacina febre amarela (DVA-VFA). Para otimizar a identificação dos casos clínicos encaminhados à investigação laboratorial foi iniciado um grupo de trabalho em 2008. O objetivo foi desenvolver uma definição padronizada de caso suspeito de DVA-VFA, com diretrizes 
para a coleta, análise e apresentação de dados, facilitando a comparação entre diversos países 53 . A DVA-VFA é um evento adverso grave e muito raro, definido como uma disfunção aguda de múltiplos órgãos que pode ocorrer após a vacinação. A gravidade varia de uma doença multissistêmica relativamente leve a uma falência grave de múltiplos órgãos e morte. A relação de causalidade da DVA com a VFA só pode ser confirmada por sequenciamento genético do vírus vacinal em espécimes clínicos do paciente, porque o quadro se confunde com o observado na infecção pelo vírus selvagem 53 . Esse é um bom exemplo de EAPV para o qual é fundamental que a investigação ocorra precocemente. Para que o diagnóstico possa ser feito, amostras de sangue devem ser coletadas logo que iniciam os sintomas, e em caso de óbito devem ser obtidas ainda amostras de vísceras. Somente com a coleta oportuna é possível atender aos critérios de definição e confirmação de caso. A dificuldade da equipe assistencial em coletar e encaminhar amostras aos laboratórios de referência faz com que muitos desses casos sejam classificados como suspeitos, sem a possibilidade de descartar a causalidade, o que pode abalar a confiança da população na vacina.

Outro exemplo da importância de utilizar definições padronizadas são os casos de anafilaxia, uma reação de hipersensibilidade aguda com envolvimento de múltiplos órgãos que pode ser grave e apresentar risco de óbito. A reação pode ocorrer após a exposição a alérgenos de uma variedade de fontes, incluindo aeroalérgenos, alimentos, drogas, imunizações e os insetos. Definir anafilaxia pode ser difícil e, se baseada apenas no julgamento clínico, pode haver discordância no diagnóstico entre médicos. Por isso, a definição de caso de anafilaxia da Colaboração Brighton é importante, pois permite a padronização, comparação e monitoramento de tendência entre os casos 54 .

No Brasil, o PNI também desenvolveu protocolos padronizados de investigação de alguns eventos adversos, como a DVA-VFA, a doença neurológica aguda associada à vacina febre amarela (DNA-VFA) e a paralisia flácida aguda após a vacina poliomielite oral atenuada. Esses protocolos orientam a identificação de casos suspeitos, coleta de exames específicos, fluxo de envio de amostras e classificação final dos casos, dando suporte às vigilâncias locais na condução do processo investigativo 6 .

\section{Dificuldades e desafios}

A vigilância de EAPV é uma atividade fundamental para garantir a segurança e a confiabilidade das vacinas em sua fase pós-comercialização. Entretanto, como já foi explicitado anteriormente, muitas são as dificuldades encontradas para que essa tarefa seja executada com sucesso.

A vigilância passiva de EAPV tem sido o tipo mais frequente de vigilância pós-mercado realizada em relação aos EAPV. O principal objetivo da vigilância passiva é detectar previamente eventos desconhecidos ou quaisquer alterações no perfil de notificação de EAPV conhecidos 55 . Devido ao seu alcance nacional, os sistemas passivos são frequentemente os únicos meios disponíveis para monitorar EAPV extremamente raros.

No entanto, os sistemas passivos têm limitações, como a subnotificação de casos, relatos de associações temporais e diagnósticos não confirmados, dados com viés (p.ex.: eventos adversos mais graves são mais provavelmente relatados que eventos menos graves) e a dificuldade em calcular taxas de incidência 55.

A subnotificação de casos de EAPV ocorre tanto no Brasil como em outros países. Um estudo nacional realizado em 2018 descreveu os EAPV do SI-EAPV (sistema de vigilância passiva) no qual foram registradas 24.732 notificações, oriundas de 2.571 municípios e que representaram menos da metade $(46,2 \%)$ do total de municípios do país reportando ao menos um EAPV ${ }^{10}$. Um trabalho realizado na República Tcheca com vigilância ativa de EAPV registrou 175 EAPV após vacinação de rotina de crianças, com uma taxa de EAPV calculada de 209/100 mil doses de vacina. Esse dado foi muito maior do que a taxa oficial de EAPV obtida por vigilância passiva pelo órgão responsável pelo registro de EAPV no país (34/100 mil doses registradas) no mesmo período do estudo, evidenciando a ocorrência de subnotificação 56 .

Um trabalho realizado na Albânia avaliou a percepção de profissionais de saúde sobre a vigilância de EAPV e as barreiras para notificação dos casos. Foi aplicado um questionário para profissionais de atenção primária $(\mathrm{n}=102)$. Dos respondentes, $70.5 \%$ disseram já ter atendido um EAPV, mas apenas 
metade destes fez o reporte do caso. Foram identificados como motivos principais para a não notificação a falta de interesse em reportar, definições pouco claras de EAPV e falta de conhecimento do que é notificável ou não 57 .

Para melhorar a captação de casos, alguns países têm utilizado novas ferramentas para realizar uma vigilância ativa. Na Austrália, o SmartVax é um sistema de monitoramento da segurança de vacinas que utiliza mensagens do tipo SMS para seguimento dos casos. Três dias após a imunização, são enviadas mensagens para os responsáveis pelas crianças vacinadas, questionando se houve alguma “reação" após a vacina. A resposta é apenas sim ou não e, caso o usuário responda "sim”, mais duas mensagens são enviadas, solicitando outras informações, ao mesmo tempo em que é gerado um alerta no sistema que direciona o caso para investigação 58 .

Vários desafios permeiam o processo de investigação de um EAPV e a primeira dificuldade é que os serviços de emergência e pronto-atendimento estejam sensíveis à possibilidade de evento adverso. Em situações de campanhas de vacinação é mais fácil sensibilizar as equipes para a suspeição de EAPV, porém na imunização de rotina muitos casos podem passar despercebidos pelas equipes assistenciais. Essa é uma fragilidade do sistema passivo de notificação e por isto alguns países como Austrália, Canadá e Cuba implementaram sistemas de vigilância ativa, com foco principalmente nas crianças 59,60,61.

Outra dificuldade do processo de investigação é o diagnóstico diferencial, essencial para estabelecer a causalidade de um EAPV e fundamental para que possam ser afastadas outras causas possíveis para os sintomas/sinais relatados 6. Por exemplo, no caso de um quadro neurológico (meningoencefalite) após a vacina febre amarela, além da pesquisa para o vírus febre amarela, outras causas de meningite bacteriana e viral devem ser pesquisadas e descartadas para permitir a confirmação de um caso de DNA-VFA.

No Brasil, o nível estadual da coordenação de imunizações é responsável por analisar, classificar segundo a causalidade e encerrar os casos de EAPV, validando os dados dos municípios. O nível federal, por sua vez, analisa e valida as notificações dos estados após o encerramento, consultando o CIFAVI e outros grupos técnicos de apoio quando necessário ${ }^{6}$.

A conclusão dos casos muitas vezes não é possível porque muitos relatos de EAPV são incompletos e faltam informações essenciais para avaliação do caso, como o lote da vacina, a data da vacinação, cronologia dos sintomas, entre outras. Em um estudo realizado na Índia, 37\% dos casos de óbitos notificados como EAPV foram encerrados como inclassificáveis, ou seja, faltavam informações para a análise de causalidade 62 . No estudo citado anteriormente sobre os EAPV do SI-EAPV, observou-se que dos 24.732 casos notificados no Brasil, somente 1.622 estavam encerrados ao final do período do estudo, isto é, apenas 6,6\% dos casos tiveram sua investigação concluída 10. Esses dados corroboram estudos anteriores, sugerindo problemas na qualidade da informação que podem incluir erros na digitação dos dados, falta de preenchimento dos campos e falhas no fluxo de informações, dificultando uma correta análise dos relatos 63,64.

Igualmente relevantes são os eventos adversos associados a erros de imunização 6. Falhas no transporte, armazenamento, manuseio e aplicação de vacinas, e na identificação de contraindicações e precauções podem não resultar em eventos adversos, mas podem contribuir para sua ocorrência. Nas campanhas de vacinação, em que há administração de quantidades de doses maiores do que na rotina, em período concentrado no tempo, com mobilização de recursos extraordinários, humanos e físicos, há possivelmente uma maior vulnerabilidade a erros de imunização que podem ser detectados somente na investigação de eventos adversos.

Um outro desafio para os programas de imunizações é a relação com a mídia e a comunidade em casos de eventos adversos que gerem comoção na sociedade. Uma saída para facilitar o manejo dessas situações é, em caso de grandes campanhas de vacinação, estabelecer um plano de gerenciamento de crise, especificando como será o manejo de casos de EAPV, caso aconteçam ${ }^{62}$. O plano deve incluir uma estratégia de comunicação, identificando o ponto focal para contato com a imprensa, comunidade e mídias sociais. Idealmente, profissionais da área de comunicação em uma assessoria de imprensa devem coordenar essa atividade com o objetivo de entregar mensagens claras e mitigar a disseminação de rumores 65 . 


\section{Conclusões}

A vigilância de EAPV é uma atividade essencial para garantir a manutenção da eficácia e segurança das vacinas.

$\mathrm{Na}$ época atual, com o retorno de doenças imunopreveníveis, o crescimento de movimentos antivacinas e a influência cada vez maior das mídias sociais na opinião pública, é muito importante que existam informações sempre atualizadas e abrangentes sobre a segurança das vacinas, que permitam aos programas de imunizações respostas rápidas e claras sobre rumores de eventos adversos.

A falta de um sistema de vigilância eficaz pode causar prejuízos incalculáveis à credibilidade de um programa de imunizações e levar a quedas importantes nas coberturas vacinais, difíceis de ser recuperadas. Os profissionais de saúde devem se conscientizar de seu importante papel nesse processo, uma vez que são a porta de entrada das informações sobre a segurança de vacinas.

O Brasil vem passando por um momento em que vemos o retorno de doenças como o sarampo e a febre amarela, e um esforço coletivo é necessário para que a descrença e o medo das vacinas sejam superados e as coberturas vacinais retornem aos níveis ideais. Para combater o medo, o melhor caminho é a informação. E a vigilância de EAPV é um componente essencial na geração das evidências necessárias para garantir ao público a eficácia e segurança das vacinas em uso no Brasil.

Ações estruturadas de vigilância de eventos adversos para a proteção do público e salvaguarda dos programas de imunizações estão consolidadas em sistemas especialmente dedicados a prover respostas rápidas e efetivas aos relatos de efeitos indesejáveis, reais ou presumidos, da aplicação de vacinas. Em que pesem os avanços alcançados, há muito espaço para melhoria, especialmente na captação e na investigação desses eventos.

\section{Colaboradores}

Todos os autores contribuíram na concepção, elaboração, revisão e aprovação da versão final.

\section{Informações adicionais}

ORCID: Patrícia Mouta Nunes de Oliveira (00000001-6867-398X); Letícia Kegele Lignani (00000001-9066-5230); Deborah Araújo da Conceição (0000-0003-0320-5397); Paula Molinari Cardoso de Mello Farias (0000-0002-1735-7626); Paulo Roberto Gomes Takey (0000-0002-9655-1696); Maria de Lourdes de Sousa Maia (0000-0003-42239151); Luiz Antonio Bastos Camacho (0000-00034656-1914).

\section{Conflito de interesses}

Os autores trabalham em Bio-Manguinhos/Fiocruz, laboratório produtor de diversas vacinas para o PNI.

\section{Agradecimentos}

Agradecemos ao Programa Nacional de Imunizações do Ministério da Saúde e aos membros da Assessoria Clínica de Bio-Manguinhos/Fiocruz pelo apoio e auxílio na elaboração deste trabalho. Os autores agradecem também a ajuda de Renata Saraiva Pedro, da Assessoria Clínica de Bio-Manguinhos/Fiocruz, pela revisão final deste artigo. 


\section{Referências}

1. World Health Organization. Global manual os surveillance of adverse events following immunization. https://apps.who.int/iris/bitstream/ handle/10665/206144/9789241507769_eng. pdf (acessado em 31/Jul/2019).

2. European Medicines Agency. Guideline on good pharmacovigilance practices (GVP). Annex I - definitions. https://www.ema.europa. eu/en/human-regulatory/post-authorisation/ pharmacovigilance/good-pharmacovigilan ce-practices\#final-gvp-annex-i---definitionssection (acessado em 31/Jul/2019).

3. Bonhoeffer J, Kohl K, Chen R, Duclos P, Heijbel $\mathrm{H}$, Heininger $\mathrm{U}$, et al. The Brighton Collaboration: addressing the need for standardized case definitions of adverse events following immunization (AEFI). Vaccine 2002; 21:298-302.

4. World Health Organization. Global vaccine safety blueprint. The landscape analysis. https://apps.who.int/iris/bitstream/han dle/10665/70854/WHO_IVB_12.04_eng.pdf (acessado em 31/Jul/2019).

5. World Health Organization. Causality assessment of an adverse event following immunization (EAFI): user manual for the revised WHO classification. https://apps.who.int/iris/bitstream/hand le/10665/259959/9789241513654-eng.pdf (acessado em 31/Jul/2019).

6. Ministério da Saúde. Manual de vigilância epidemiológica de eventos adversos pós-vacinação. http://biblioteca.cofen.gov.br/manualde-vigilancia-epidemiologica-de-eventos-ad versos-pos-vacinacao/ (acessado em 24/Mai/ 2018).

7. World Health Organization. The importance of pharmacovigilance - safety monitoring of medicinal products. http://apps.who.int/ medicinedocs/en/d/js4893e/ (acessado em 17/ Mai/2018).

8. Arif N, Al-Jefri M, Bizzi IH, Perano GB, Goldman M, Haq I, et al. Fake news or weak science? Visibility and characterization of antivaccine webpages returned by Google in different languages and countries. Front Immunol 2018; 9:1215.

9. Lei J, Balakrishnan MR, Gidudu JF, Zuber PLF. Use of a new global indicator for vaccine safety surveillance and trends in adverse events following immunization reporting 2000-2015. Vaccine 2018; 36:1577-82.

10. Pacheco FC, Domingues CMAS, Maranhão AGK, Carvalho SMD, Teixeira AMS, Braz RM, et al. Análise do Sistema de Informação da Vigilância de Eventos Adversos Pós-Vacinação no Brasil, 2014 a 2016. Rev Panam Salud Pública 2018 ; 42:e12.
11. Agência Nacional de Vigilância Sanitária. Notivisa - Sistema Nacional de Notificações para a Vigilância Sanitária. Anexo 3. Formulário para notificação de eventos adversos à medicamento - profissional da saúde. http:// www.anvisa.gov.br/hotsite/notivisa/manual/ ea_medicamento_profissional.pdf (acessado em 02/Mai/2019).

12. Agência Nacional de Vigilância Sanitária. Guias de farmacovigilância para detentores de registro de medicamentos. http://portal. anvisa.gov.br/documents/33868/2894051/ Guias+de+Farmacovigil\%C3\%A2ncia+para+ Detentores + de+Registro+de+Medicamen tos+-+documento+completo/f3fc06a5-97e 6-4bbc-848d-750bcefb99e0 (acessado em 21/ Jan/2020).

13. Ministério da Saúde; Agência Nacional de Vigilância Sanitária. Resolução da Diretoria Colegiada - RDC no 4, de 10 de fevereiro de 2009. Dispõe sobre as normas de farmacovigilância para os detentores de registro de medicamentos de uso humano. Diário Oficial da União 2009; 11 fev.

14. Brown AL, Sperandio M, Turssi CP, Leite RMA, Berton VF, Succi RM, et al. Vaccine confidence and hesitancy in Brazil. Cad Saúde Pública 2018; 34:e00011618.

15. Sociedade Brasileira de Imunizações; Avaaz. As fake news estão nos deixando doentes? Como a desinformação antivacinas pode estar reduzindo as taxas de cobertura vacinal no Brasil. https://sbim.org.br/images/files/poavaaz-relatorio-antivacina.pdf (acessado em 21/Jan/2020).

16. Ministério da Saúde. Fake news. http://www. saude.gov.br/fakenews/ (acessado em 21/ Jan/2020).

17. Brighton Collaboration Foundation. The Brighton Collaboration. https:// www.brightoncollaboration.org/search. html?queryStr $=$ case + definitions (acessado em 31/Jul/2019).

18. Waldman EA, Luhm KR, Monteiro SAMG, Freitas FRM. Surveillance of adverse effects following vaccination and safety of immunization programs. Rev Saúde Pública 2011; 45:173-84.

19. Baker MA, Kaelber DC, Bar-Shain DS, Moro PL, Zambarano B, Mazza M, et al. Advanced clinical decision support for vaccine adverse event detection and reporting. Clin Infect Dis 2015; 61:864-70.

20. Uppsala Monitoring Centre. WHO Programme for International Drug Monitoring. https:// www.who-umc.org/global-pharmacovigi lance/who-programme-for-internationaldrug-monitoring/ (acessado em 23/Jan/2020). 
21. Lankinen KS, Pastila S, Kilpi T, Nohynek H, Mäkelä PH, Olin P. Vaccino vigilance in Europe - need for timeliness, standardization and resources. Bull World Health Organ 2004; 82:828-35.

22. European Medicines Agency. EudraVigilance system overview. https://www.ema.europa.eu/ en/human-regulatory/research-development/ pharmacovigilance/eudravigilance/eudra vigilance-system-overview (acessado em 31/ $\mathrm{Jul} / 2019$ ).

23. Centers for Disease Control and Prevention. Parents questions answered. Vaccines for Children Program. https://www.cdc.gov/vaccines/ programs/vfc/parents/qa-detailed.html (acessado em 13/Ago/2019).

24. World Health Organization. Global Vaccine Action Plan - Secretariat Annual Report. https://www.who.int/immunization/sage/ meetings/2017/october/3_GVAP_SecRep ort2017.pdf (acessado em 13/Ago/2019).

25. World Health Organization. WHO Global Vaccine Action Plan Monitoring, Evaluation \& Ac countability. https://www.who.int/immuniza tion/global_vaccine_action_plan/web_gvap_ secretariat_report_2018.pdf (acessado em 13/ Ago/2019).

26. Destefano F, Offit PA, Fisher A. Vaccine safety. In: Ploktin S, Orenstein W, Offit P, Edwards $\mathrm{KM}$, editors. Plotkin's vaccines. 7th Ed. Amsterdam: Elsevier; 2018. p. 1584-600.

27. Silva Junior JB. 40 anos do Programa Nacional de Imunizações: uma conquista da saúde pública brasileira. Epidemiol Serv Saúde 2013; 22:7-8.

28. Secretaria de Vigilância em Saúde, Ministério da Saúde. Portaria no 33, de 14 de julho de 2005. Diário Oficial da União 2005; 15 jul.

29. Ministério da Saúde. Portaria no 204, de 17 de fevereiro de 2016. Define a Lista Nacional de Notificação Compulsória de doenças, agravos e eventos de saúde pública nos serviços de saúde públicos e privados em todo o território nacional, nos termos do anexo, e dá outras providências. Diário Oficial da União 2016; 18 fev.

30. Ministério da Saúde; Agência Nacional de Vigilância Sanitária; Fundação Oswaldo Cruz. Portaria Conjunta no 92, de 9 de outubro de 2008. Dispõe sobre o estabelecimento de mecanismo de articulação entre a Agência Nacional de Vigilância Sanitária, a Secretaria de Vigilância em Saúde e o Instituto Nacional de Controle de Qualidade em Saúde da Fundação Oswaldo Cruz sobre Farmacovigilância de Vacinas e outros Imunobiológicos no âmbito do Sistema Único de Saúde e define suas competências. Diário Oficial da União 2008; 10 out.

31. Agência Nacional de Vigilância Sanitária. Boletim de Farmacovigilância 2011; (1). http://por tal.anvisa.gov.br/documents/33868/2894786/ Boletim+de+Farmacovigil\%C3\%A2ncia+n\% C2\%BA+01/ec9f5a88-7c65-40a1-80a3-30e fa9aea1c4.
32. Agência Nacional de Vigilância Sanitária. Anvisa é novo membro do ICH. http://portal. anvisa.gov.br/rss/-/asset_publisher/Zk4q6U QCj9Pn/content/com-o-inicio-da-reformado-ich-a/219201?inheritRedirect=false (acessado em 01/Ago/2019).

33. Medical Dictionary for Regulatory Activities. Support documentation. https://www.med dra.org/how-to-use/support-documentation (acessado em 01/Ago/2019).

34. World Health Organization. Health Information Systems, 2008. https://www.who.int/ healthinfo/statistics/toolkit_hss/EN_PDF_ Toolkit_HSS_InformationSystems.pdf (acessado em 01/Ago/2019).

35. Cunha S, Dourado I, Barreto ML, Teixeira G, Melo A, Lucena R, et al. Associação entre meningite asséptica e uso da vacina tríplice viral (sarampo-caxumba-rubéola) durante campanha vacinal de 1997. Inf Epidemiol SUS 1998; 7:29-61.

36. Dourado I, Cunha SS, Maia MLS, Lima KMB, Soares BAC, Barreto ML. Eventos adversos associados à vacina tríplice viral com cepa Leningrad-Zagreb nos estados de Mato Grosso e Mato Grosso do Sul, durante as campanhas de imunização de 1998. Epidemiol Serv Saúde 2004; 13:47-55.

37. World Health Organization. Rotavirus vaccines and intussusception. https://www.who. int/vaccine_safety/committee/topics/rotavi rus/rotarix_and_rotateq/Dec_2011/en/ (acessado em 01/Ago/2019).

38. Ministério da Saúde. Boletim Epidemiológico 2015; 46(42). http://portalarquivos.saude.gov. $\mathrm{br} / \mathrm{images} / \mathrm{pdf} / 2015 / \mathrm{dezembro} / 11 / \mathrm{svs}-\mathrm{be}$ 2015-047-dengue-se47-final.pdf.

39. Centers for Disease Control and Prevention. Vaccines: VPD-VAC/Rotavirus/Rotashield and Intussusception Historical info. https:// www.cdc.gov/vaccines/vpd-vac/rotavirus/ vac-rotashield-historical.htm (acessado em 01/ Ago/2019).

40. Patel MM, López-Collada VR, Bulhões MM, de Oliveira LH, Márquez AB, Flannery B, et al. Intussusception risk and health benefits of rotavirus vaccination in Mexico and Brazil. $\mathrm{N}$ Engl J Med 2011; 364:2283-92.

41. Agência Nacional de Vigilância Sanitária. Vacina da dengue terá alteração de bula. http:// portal.anvisa.gov.br/rss/-/asset_publisher/ Zk4q6UQCj9Pn/content/vacina-da-denguetera-alteracao-de-bula/219201?inheritRedi rect=false (acessado em 01/Ago/2019).

42. Aguiar M, Stollenwerk N, Halstead SB. The risks behind Dengvaxia recommendation. Lancet Infect Dis 2016; 16:882-3.

43. Hadinegoro SR, Arredondo-García JL, Capeding MR, Deseda C, Chotpitayasunondh T, Dietze R, et al. Efficacy and long-term safety of a dengue vaccine in regions of endemic disease. N Engl J Med 2015; 373:1195-206. 
44. Halstead SB. Dengvaxia sensitizes seronegatives to vaccine enhanced disease regardless of age. Vaccine 2017; 35:6355-8.

45. Halstead SB, Russell PK. Protective and immunological behavior of chimeric yellow fever dengue vaccine. Vaccine 2016; 34:1643-7.

46. Agência Nacional de Vigilância Sanitária. Vacina dengue: esclarecimentos. http:// portal.anvisa.gov.br/rss/-/asset_publisher/ Zk4q6UQCj9Pn/content/vacina-dengue-es clarecimentos $/ 219201$ ? inheritRedirect $=$ false (acessado em 01/Ago/2019).

47. Aguiar M, Halstead SB, Stollenwerk N. Consider stopping dengvaxia administration without immunological screening. Expert Rev Vaccines 2017; 16:301-2.

48. Martins RM, Camacho LAB, Lemos MCF, Noronha TG, Carvalho MHC, Greffe N, et al. Incidence of hypotonic-hyporesponsive episodes associated to the combined DTP/ $\mathrm{Hib}$ vaccine used in Brazilian National Immunizations Program. J Pediatr (Rio J.) 2007; 83:523-8.

49. Sato APS, Ferreira VLR, Tauil MC, Rodrigues LC, Barros MB, Martineli E, et al. Use of electronic immunization registry in the surveillance of adverse events following immunization. Rev Saúde Pública 2018; 52:4.

50. Organização Pan-Americana da Saúde. Boas práticas de farmacovigilância para as Américas. Washington DC: Organização Pan-Americana da Saúde; 2011.

51. World Health Organization. Data causality assessment of adverse event following immunization (AEFI): user manual for the revised WHO classification. https://www.who.int/ vaccine_safety/publications/aefi_manual.pdf (acessado em 01/Ago/2019).

52. Brighton Collaboration Foundation. History. https://www.brightoncollaboration. org/about-us/history.html (acessado em 01/ Ago/2019).

53. Gershman MD, Staples JE, Bentsi-Enchill AD, Breugelmans JG, Brito GS, Camacho LAB, et al. Viscerotropic disease: case definition and guidelines for collection, analysis, and presentation of immunization safety data. Vaccine 2012; 30:5038-58.

54. Rüggeberg JU, Gold MS, Bayas J-M, Blum MD, Bonhoeffer J, Friedlander S, et al. Anaphylaxis: case definition and guidelines for data collection, analysis, and presentation of immunization safety data. Vaccine 2007; 25:5675-84.

55. Griffin MR, Braun MM, Bart KJ. What should an ideal vaccine postlicensure safety system be? Am J Public Health 2009; 99 Suppl 2:S345-50.

56. Danova J, Kocourkova A, Celko AM. Active surveillance study of adverse events following immunisation of children in the Czech Republic. BMC Public Health 2017; 17:167.

57. Mehmeti I, Nelaj E, Simaku A, Tomini E, Bino S. Knowledge, practice and approaches of health professionals to adverse events following immunization and their reporting in Albania. Heliyon 2017; 3:e00331.
58. Westphal DW, Williams SA, Leeb A, Effler PV. Continuous active surveillance of adverse events following immunisation using SMS technology. Vaccine 2016; 34:3350-5.

59. Public Health Agency of Canada. Provincial and Territorial Immunization Information. https://www.canada.ca/en/public-health/ services/provincial-territorial-immunizationinformation.html (acessado em 31/Jul/2019).

60. Department of Health, Australian Government. National Immunisation Program Schedule. https://www.health.gov.au/health-topics/ immunisation/immunisation-throughout-life/ national-immunisation-program-schedule (acessado em 31/Jul/2019).

61. World Health Organization. WHO vaccinepreventable diseases: monitoring system. 2020 global summary. Cuba. http://apps.who.int/ immunization_monitoring/globalsummary/ countries? countrycriteria\%5Bcountry\%5D\%5 B\%5D=CUB (acessado em 28/Jan/2020).

62. Singh AK, Wagner AL, Joshi J, Carlson BF, Aneja S, Boulton ML. Causality assessment of serious and severe adverse events following immunization in India: a 4-year practical experience. Expert Rev Vaccines 2018; 17:555-62.

63. Silva SS, Oliveira VC, Ribeiro HCTC, Alves TGS, Cavalcante RB, Guimarães EAA, et al. Análise dos eventos adversos após aplicação de vacinas em Minas Gerais, 2011: um estudo transversal. Epidemiol Serv Saúde 2016; 25:45-54.

64. Araújo TME, Carvalho PMG, Vieira RDF. Análise dos eventos adversos pós-vacinais ocorridos em Teresina. Rev Bras Enferm 2007; 60:444-8.

65. Loharikar A, Suragh TA, MacDonald NE, Balakrishnan MR, Benes O, Lamprianou S, et al. Anxiety-related adverse events following immunization (AEFI): a systematic review of published clusters of illness. Vaccine 2018; 36:299-305.

66. Therapeutic Goods Administration. Australian Adverse Drug Reaction Reporting System. https://www.ebs.tga.gov.au/ebs/ADRS/ ADRSRepo.nsf? (acessado em 14/Ago/2019).

67. Department of Health, Australian Government. Adverse events following immunisation annual reports. https://www1.health.gov.au/ internet/main/publishing.nsf/Content/cdaaefi-anrep.htm (acessado em 14/Ago/2019).

68. Ministério da Saúde. Sobre o programa. http://www.saude.gov.br/saude-de-a-z/vaci nacao/sobre-o-programa (acessado em 14/ Ago/2019).

69. Public Health Agency of Canada. Canadian Adverse Events Following Immunization Surveillance System (CAEFISS). https://www. canada.ca/en/public-health/services/immu nization/canadian-adverse-events-followingimmunization-surveillance-system-caefiss. html (acessado em 14/Ago/2019). 
70. World Health Organization. Immunization country profile. https://apps.who.int/immuni zation_monitoring/globalsummary/countries ?countrycriteria\%5Bcountry\%5D\%5B $\% 5 \mathrm{D}=\mathrm{C}$ HN (acessado em 14/Ago/2019).

71. Ministerio de Sanidad, Consumo y Bienestar Social. Programa Vacunación 2019. https:// www.mscbs.gob.es/profesionales/saludPubli $\mathrm{ca} /$ prevPromocion/vacunaciones/home.htm (acessado em 14/Ago/2019).

72. Centro para el Control Estatal de Medicamentos. Vigilancia. https://www.cecmed.cu/vigi lancia (acessado em 14/Ago/2019).

73. Centers for Disease Control and Prevention. Vaccine Adverse Event Reporting System (VAERS). https://www.cdc.gov/vaccinesafety/ ensuringsafety/monitoring/vaers/index.html (acessado em 23/Jan/2020).

74. Food and Drug Authority Ghana. Monitoring of adverse events following immunization in Ghana. https://fdaghana.gov.gh/images/sto ries/pdfs/Safety\%20Monitoring/2018/Moni toring\%20of\%20Adverse\%20Events\%20\%20 09032018.pdf (acessado em 14/Ago/2019).

75. Ministry of Health and Family Welfare. Revised AEFI Guidelines Execute Summary. https://mohfw.gov.in/sites/default/files/Re vised\%20AEFI\%20Guidelines\%20Execute\%20 Summary.pdf (acessado em 14/Ago/2019).

76. World Health Organization. WHO vaccinepreventable diseases: monitoring system. 2019 global summary. https://apps.who.int/immu nization_monitoring/globalsummary/coun tries? countrycriteria\%5Bcountry\%5D\%5B\% 5D=PAK (acessado em 14/Ago/2019).

77. Government of Pakistan. Our future plans Expanded Program on Immunization, Pakistan. http://www.epi.gov.pk/immunisationschedule/ (acessado em 31/Jul/2019).

78. Government of the United Kingdom. Report a problem with a medicine or medical device. https://www.gov.uk/report-problemmedicine-medical-device (acessado em 14/ Ago/2019).
79. European Medicines Agency. European database of suspected adverse drug reaction reports. http://www.adrreports.eu/en/index. html (acessado em 14/Ago/2019).

80. World Health Organization. WHO vaccinepreventable diseases: monitoring system. 2020 global summary. https://apps.who.int/immu nization_monitoring/globalsummary (acessado em 14/Ago/2019).

81. Ministério da Saúde. Calendário Nacional de Vacinação. http://www.saude.gov.br/saude-de -a-z/vacinacao/calendario-vacinacao (acessado em 31/Jul/2019).

82. Centers for Disease Control and Prevention. Recommended child and adolescent immunization schedule for ages 18 years or younger, United States, 2020. https://www.cdc.gov/ vaccines/schedules/hcp/imz/child-adolescent. html (acessado em 31/Jul/2019).

83. Government of the United Kingdom. Complete_immunisation_schedule_sept 2018 . pdf. https://assets.publishing.service.gov.uk/ government/uploads/system/uploads/attach ment_data/file/741543/Complete_immunisa tion_schedule_sept2018.pdf (acessado em 31/ $\mathrm{Jul} / 2019$ ).

84. Secretaría de Salud. Esquema de vacunación. http://www.gob.mx/salud/articulos/esquemade-vacunacion (acessado em 31/Jul/2019).

85. World Health Organization. WHO vaccinepreventable diseases: monitoring system. 2020 global summary. Ghana. http://apps.who.int/ immunization_monitoring/globalsummary/ countries? countrycriteria\% $5 \mathrm{~B}$ country\% 5D\%5B\%5D=GHA (acessado em 28/Jan/2020).

86. Ministry of Health and Family Welfare. Universal immunisation programme. https:// www.nhp.gov.in/universal-immunisationprogramme_pg (acessado em 31/Jul/2019).

87. World Health Organization. AEFI investigation. https://www.who.int/vaccine_safety/pu blications/AEFI_Investigation_Aide_Memoi re.pdf (acessado em 24/Jan/2020). 


\section{Abstract}

Immunization is one of the most effective measures to protect individuals and the population against vaccine-preventable diseases. Vaccines are safe and effective products, but like any other drug they can cause adverse events, which tend to become more visible as the diseases are controlled, eliminated, or eradicated. This study analyzed activities in the surveillance of adverse events following immunization (AEFI) based on data from the scientific literature, websites of immunization programs and health and regulatory agencies, and the authors' expertise in the areas of immunizations and pharmacovigilance. With the increase in the number of vaccines in the basic immunization schedule and expansion of the population's access, it has become essential to establish an efficient surveillance system for AEFI in Brazil. However, underreporting of cases in Brazil and in other countries hinders the detection of AEFI, especially rare events. Constantly updated information on vaccines' risks and benefits allows immunization programs to provide rapid and clear responses to rumors of AEFI. This ensures the system's reliability, especially in the face of the growing antivaccine movement and the increasing influence of social media in public opinion.

Immunization; Immunization Programs;

Postmarketing Product Surveillance

\section{Resumen}

La vacunación es una de las acciones más efectivas para proteger al individuo y a la población contra enfermedades inmunoprevenibles. Las vacunas son productos seguros y eficaces, sin embargo, como cualquier otro medicamento, pueden causar eventos adversos, que tienen mayor visibilidad según se controlen, eliminen o se erradiquen las enfermedades. Este trabajo analizó las acciones de vigilancia de eventos adversos posvacunación (EAPV), basándose en datos de la literatura científica y sitios web de programas de inmunizaciones, agencias reguladoras y de salud, además de la expertise de los autores en las áreas de inmunizaciones y farmacovigilancia. Con el aumento del número de vacunas en el calendario básico y la ampliación del acceso de la población, se hizo fundamental el estabelecimiento de un sistema eficiente de vigilancia de EAPV en Brasil. Sin embargo, la subnotificación de casos en Brasil y en otros países dificulta la detección de EAPV, principalmente, los raros. Informaciones siempre actualizadas sobre el beneficio/riesgo de las vacunas permiten que programas de inmunizaciones proporcionen respuestas rápidas y claras a los rumores sobre EAPV. Esto garantiza la confianza en el sistema, incluso más aún ante el creciente movimiento antivacunas y la influencia cada vez mayor de los redes sociales en la opinión pública.

Inmunización; Programas de Inmunización; Vigilancia de Productos Comercializados
Recebido em 19/Set/2019

Versão final reapresentada em 06/Fev/2020

Aprovado em 14/Fev/2020 